\title{
Effect of Processing Temperature and the Content of Carbon Nanotubes on the Properties of Nanocomposites Based on Polyphenylene Sulfide
}

\author{
Kamil Dydek ${ }^{1, *} \mathbb{C}$, Paulina Latko-Durałek ${ }^{1}\left(\mathbb{D}\right.$, Agata Sulowska $^{1}$, Michał Kubis ${ }^{2}{ }^{\circledR}$, Szymon Demski ${ }^{1}$, \\ Paulina Kozera ${ }^{1}$, Bogna Sztorch ${ }^{3}$ and Anna Boczkowska ${ }^{1}$ (D) \\ 1 Faculty of Materials Science and Engineering, Warsaw University of Technology, 141 Wołoska, \\ 02-507 Warsaw, Poland; paulina.latko@pw.edu.pl (P.L.-D.); agata.sulowska.stud@pw.edu.pl (A.S.); \\ szymon.demski.dokt@pw.edu.pl (S.D.); paulina.kozera@pw.edu.pl (P.K.); anna.boczkowska@pw.edu.pl (A.B.) \\ 2 Faculty of Power and Aeronautical Engineering, Warsaw University of Technology, 24 Nowowiejska, \\ 00-665 Warsaw, Poland; michal.kubis@pw.edu.pl \\ 3 Centre for Advanced Technologies, Adam Mickiewicz University in Poznań, 10 Uniwersytetu Poznańskiego, \\ 61-614 Poznań, Poland; bognasztorch@gmail.com \\ * Correspondence: kamil.dydek@pw.edu.pl
}

Citation: Dydek, K.; Latko-Durałek, P.; Sulowska, A.; Kubiś, M.; Demski, S.; Kozera, P.; Sztorch, B.; Boczkowska, A. Effect of Processing Temperature and the Content of Carbon Nanotubes on the Properties of Nanocomposites Based on Polyphenylene Sulfide. Polymers 2021, 13, 3816. https://doi.org/10.3390/ polym13213816

Academic Editors: Somen K. Bhudolia and Sunil Chandrakant Joshi

Received: 13 October 2021

Accepted: 2 November 2021

Published: 4 November 2021

Publisher's Note: MDPI stays neutra with regard to jurisdictional claims in published maps and institutional affiliations.

Copyright: (c) 2021 by the authors. Licensee MDPI, Basel, Switzerland. This article is an open access article distributed under the terms and conditions of the Creative Commons Attribution (CC BY) license (https:// creativecommons.org/licenses/by/ $4.0 /)$.
Abstract: The study aimed to investigate the effect of processing temperature and the content of multi-wall carbon nanotubes (MWCNTs) on the rheological, thermal, and electrical properties of polyphenylene sulfide (PPS)/MWCNT nanocomposites. It was observed that the increase in MWCNT content influenced the increase of the complex viscosity, storage modulus, and loss modulus. The microscopic observations showed that with an increase in the amount of MWCNTs, the areal ratio of their agglomerates decreases. Thermogravimetric analysis showed no effect of processing temperature and MWCNT content on thermal stability; however, an increase in stability was observed as compared to neat PPS. The differential scanning calorimetry was used to assess the influence of MWCNT addition on the crystallization phenomenon of PPS. The calorimetry showed that with increasing MWCNT content, the degree of crystallinity and crystallization temperature rises. Thermal diffusivity tests proved that with an increase in the processing temperature and the content of MWCNTs, the diffusivity also increases and declines at higher testing temperatures. The resistivity measurements showed that the conductivity of the PPS/MWCNT nanocomposite increases with the increase in MWCNT content. The processing temperature did not affect resistivity.

Keywords: PPS; carbon nanotubes; thermal analysis; electrical properties; rheological properties

\section{Introduction}

Modern technological developments have created a need for new materials or the expansion of parameters and functional features of currently available products. In recent years, high-performance thermoplastics, also known as engineering polymers, have been the subject of study for many scientists. This was a result of the exceptional properties of the polymers, their ease of forming, and many possibilities of modifications. Polymers containing aromatic units, such as polyether ether ketone (PEEK), polyphenylene sulfide (PPS), and poly(ether sulfone) (PES), are widely used in electrical [1], automotive [2], and chemical industries [3,4]. Polyphenylene sulfide (PPS) is one of the most used engineering semi-crystalline thermoplastic due to its properties and relatively high temperature resistance (melting point $275^{\circ} \mathrm{C}$ ) [5,6]. PPS has good chemical resistance to most organic solvents, including alcohols, ketones, chlorinated aliphatic compounds, esters, and liquid ammonia [7]. It is also resistant to atmospheric factors, such as moisture and UV radiation. It has a low coefficient of thermal expansion and is, therefore, a material with excellent dimensional stability. Its natural non-flammability is also an advantage in many applications [8,9]. Although neat PPS possess exceptional properties, in the case of many 
applications, they are insufficient; thus, a great deal of research focuses on improving them or adding new functional properties through the modification of PPS [10].

One of the most popular methods of PPS modification is the production of polymer blends [11]. J. Z. Liang [12] manufactured PPS/Polycarbonate (PC) blends to investigate the influence of PC content on heatproof properties. It has been demonstrated that when the PC weight fraction is less than $20 \%$, the distortion temperature of the PPS/PC blend is lower than that of neat PPS. The reason is the lower heatproof property of PC than PPS and an insufficient number of physical nodes of the macromolecular chains between the PPS and PC. The number of nodes will increase with higher PC content, resulting in an improved heatproof property. Z. Ma et al. [13] fabricated microcellular foams from high-performance PPS/PEEK blends and compared their performance with solid PPS/PEEK blends. The conclusion was that PEEK could improve the impact toughness of the PPS blend due to their interaction, and the presence of PEEK greatly accelerates the crystallization process of PPS. Microcellular foaming improves the crystallinity, specific tensile strength, and impact strength of the PPS/PEEK blends and decreases the storage modulus and loss factor. Another method of PPS modification is the production of PPS composites with inorganic fillers, i.e., $\mathrm{TiO}_{2}$ and $\mathrm{ZnO}$. This solution allows for a significant improvement in tribological properties compared to pure PPS-by adding $6 \mathrm{wt} \%$ of $\mathrm{TiO}_{2}$, the material wear index was reduced 100 times, so it can be successfully used in bearings, brake pads, and gears $[14,15]$.

Although methods of improving parameters are available and a new application of PPS blends and composites is observed, there are still areas that require new modifications, e.g., in the field of conductive materials. The electrical performance of polymer matrix composites (PMCs) can be improved by adding metal or carbon particles, i.e., carbon nanotubes (CNTs). R. K. Goyal et al. [16] prepared PPS composites with copper (Cu) particles by first mixing and then injection molding to investigate the influence of metal particles on various properties of composites, including electrical properties. The results showed that the percolation threshold is around $6 \mathrm{vol} \%$ of $\mathrm{Cu}$ particles and the electrical conductivity increases to $18.5 \mathrm{vol} \%$ of $\mathrm{Cu}$ particles due to the infinite conductive cluster in the matrix. However, on further increasing the $\mathrm{Cu}$ content, the conductivity decreased due to the porosity of the composite. J. Yang et al. [17] obtained (PPS)/multi-wall carbon nanotube (MWCNT) nanocomposites by melt mixing PPS with raw MWCNTs without any pre-treatment, to investigate the mechanical and electrical properties of such composites. The melt blending of PPS with MWCNTs was conducted using a mixer at a temperature of $300{ }^{\circ} \mathrm{C}$ for $10 \mathrm{~min}$. Considering electrical properties, it was observed that there is a gradual decrease of resistivity before MWCNTs is increased to $5 \mathrm{wt} \%$. Then, a sharp decrease of the resistivity of almost five orders of magnitude (from $10^{-12}$ to $10^{-7} \Omega \cdot \mathrm{cm}$ ) was achieved, as the content was increased from 5 to $7 \mathrm{wt} \%$. However, with a higher MWCNT content, only an insignificant decrease in resistivity was observed. M. Park et al. [18] investigated the enhancement of PPS composites' interfacial, electrical, and flexural properties by introducing CFs coated with MWCNTs based on electrophoresis. PPS composites filled with seized CFs or with CFs coated with MWCNTs were fabricated using a twin-screw extruder. The interfacial shear strength of the PPS composites was improved by about $41.7 \%$ due to the MWCNTs introduced on the surface of CFs. Introducing MWCNTs on the CF surface improved the electrical conductivity of the composites by about $78 \%$, probably because MWCNTs are excellent electrically conductive fillers. Additionally, the percolation threshold of the PPS composites filled with the MWCNT coated CFs based on electrophoresis was lower than that of PPS composites filled with resized CFs. Moreover, low thermal conductivity, which is characteristic of polymers, limits a range of applications in many cases where heat dissipation is required. This parameter can also be modified by using highly thermally conductive fillers. Y. Seki et al. [19] prepared PPS-based composites modified with a maximum of $5 \mathrm{wt} \%$ of synthetic graphite that showed an approximately triple increase in thermal diffusivity in the through-thickness direction and the 32-fold larger increase for the in-plane direction compared with neat PPS. S. Deng et al. [20] demonstrated an impact of graphene nanoplates on the thermal conductivity of PPS. 
Thermal conductivity for the neat matrix was reported as $0.219 \mathrm{~W} \mathrm{~m} \mathrm{~m}^{-1} \cdot \mathrm{K}^{-1}$. It increased up to $1.156 \mathrm{~W} \mathrm{~m} \mathrm{~m}^{-1} \cdot \mathrm{K}^{-1}$ in the case of $30 \mathrm{wt} \%$ content of graphene nanoplates. G. Junwei [21] presented even higher thermal conductivity for PPS/Graphene nanoplates composite. An almost 20 -fold increase in thermal conductivity was achieved by using a similar weight fraction of filler.

Another example of processing of PPS composites is to use them in the form of fibers, which combine moderate thermal properties with excellent chemical resistance, but few studies have included the modification with a high volume of carbon nanotubes (CNT). Xing et al. [22] manufactured PPS fibers with functionalized graphene nanoplatelets (GNPs) via melt spinning to improve the oxidation resistance of the composite. The result shows that the addition of GNPs influences the surface roughness of fibers and increases the degree of crystallinity of PPS. Kulpinski et al. [6] manufactured PPS fibers and nonwovens by the melt-blown method modified with CNT and carbonyl iron microparticles at low content (up to $1 \mathrm{wt} \%$ ). The mechanical properties of fibers with fillers were worse than neat PPS because of the chosen production method. The addition of CNTs improved the electrical properties of fibers, and manufactured nonwovens obtained electromagnetic properties. EMI shielding of nonwovens was tested and the results were satisfying. Moreover, PPS can be also used as a material for the filament to 3D printing [23]. Parans Paranthaman et al. used PPS $/ \mathrm{NbFeB}$ composites to produce permanent magnets using the FDM technique [24].

The aim of this article is to optimize the processing temperature of PPS/MWCNT nanocomposites and the content of MWCNTs so that in the developed material, it would be possible to successfully produce nanocomposite fibers, which in the next stage will be used to produce conductive, thermoplastic nonwovens using the thermo-pressing method [25]. Thermoplastic nonwovens containing MWCNTs can be used as interlayers or surface finish to modify carbon fiber reinforced polymers (CFRPs) to improve electrical and mechanical properties [26-28]. Quan et al. [29] used PPS/MWCNT nonwovens produced wet-laid process, where the MWCNTs were applied using the airbrush technique, and then, the nonwovens were used to improve the properties of CFRP composites. In the case of improving the electrical properties, thermoplastic nonwovens with the addition of MWCNTs allow the creation of conductive paths between the layers of carbon fibers, which in turn reduces the CFRP resistivity [30]. Additionally, no reports were found in the literature about the impact of processing using a twin-screw extruder on the properties of PPS/MWCNT nanocomposites. To sum up, the use of PPS/MWCNT nanocomposites as a material for the production of thermoplastic nonwovens by thermo-pressing method is an innovative approach, so far unheard of in the literature, which justifies the need to select and optimize the processing temperature as well as the content of MWNCTs in PPS/MWCNT nanocomposites in order to verify their functional properties.

\section{Materials and Methods}

\subsection{Materials}

Fortron ${ }^{\circledR}$ PPS (Celanese, Pasadena, TX, USA) was used as a polymer matrix to produce PPS/MWCNT nanocomposites, whereas MWCNTs with the trade name NC7000 from Nanocyl (Sambreville, Belgium), synthesized through catalytic carbon vapor deposition process, were used as a conductive nanofiller. The average diameter of an MWCNT is $9.5 \mathrm{~nm}$, its length is $1.5 \mu \mathrm{m}$, and its purity $>95 \%$. Additionally, Nanocyl manufactured and delivered masterbatch in the form of pellets, using a semi-industrial production line equipped with a twin-screw extruder. The masterbatch contained $10 \mathrm{wt} \%$ MWCNT. Then, using the laboratory twin-screw extruder HAAKE MiniLab (ThermoFisher Scientific, Waltham, MA, USA), mixing neat PPS with delivered masterbatch, nanocomposites PPS/MWCNT were produced with the following MWCNT concentrations: $2 \mathrm{wt} \%, 4 \mathrm{wt} \%$, $6 \mathrm{wt} \%$, and $8 \mathrm{wt} \%$. Moreover, to check the impact of the processing conditions, three different temperatures were applied: 290,305 , and $320^{\circ} \mathrm{C}$ at a constant rotational speed of the screws, which was $50 \mathrm{rpm}$. To investigate the effect of the processing temperature on 
the dispersion of MWCNTs in the polymer matrix, the masterbatch was also extruded at three different temperatures, namely 290,305 , and $320^{\circ} \mathrm{C}$.

The test specimens were produced using a laboratory HAAKE MiniJet Pro (Thermo Fisher Scientific) injection molding machine, where the mold temperature was $140{ }^{\circ} \mathrm{C}$, and the injection and hold pressures were 800 and 700 bar, respectively. The temperatures in the cylinder, where the material was plasticized, were 290,305 , and $320^{\circ} \mathrm{C}$, corresponding to the processed nanocomposite material.

\subsection{Measurement Methods}

The rheological properties of the material were measured using an oscillatory ARES rheometer (Rheometric Scientific Inc., TA Instruments, New Castle, DE, USA) in parallel plate geometry mode. Firstly, the amplitude sweep test was performed, to choose the appropriate strain values from the linear elastic range. Afterward, using the selected strain $(10 \%)$, a dynamic oscillatory stress-controlled rotational test was performed at $320^{\circ} \mathrm{C}$ with a frequency sweep from 0.1 to $100 \mathrm{~Hz}$. To examine how the addition of MWCNTs affects the rheological properties of PPS, the complex viscosity, storage modulus, and loss modulus were collected. Specimens for the rheological analysis were prepared directly from the pellets by injection molding into rounds having a diameter of $1.5 \mathrm{~mm}$ and a thickness of $2 \mathrm{~mm}$.

The state of MWCNTs' dispersion has been characterized by transmission optical microscopy. Samples were prepared using Ultramicrotome Leica EM UC6 (Leica Microsystems, Wetzlar, Germany) equipped with a chamber for low-temperature processing. The materials were cut with a diamond knife at the temperature $-10^{\circ} \mathrm{C}$ into slides with $2 \mu \mathrm{m}$ thickness. Furthermore, samples were deposited on the surface of a microscopic glass and observed through a light transmission microscope PZO Biolar (Biolar, Warsaw, Poland). The optical micrographs were analyzed using the digital image processing software ImageJ (National Institutes of Health and the Laboratory for Optical and Computational Instrumentation, Madison, WI, USA). The MWCNTs' agglomerate area ratio was defined as the ratio of the cumulative area of the MWCNTs' agglomerate system relating to the micrograph area, and this ratio was presented in a percentage [31]. Only MWCNT agglomerates with diameters higher than $1 \mu \mathrm{m}$ were used for analysis. To have sufficient statistics of measured values, at least seven optical illustrating micrographs were used for calculation.

The thermal stability of the PPS/MWCNT composites was investigated by thermogravimetric analysis (TGA) using a TGA Q500 (TA Instruments, New Castle, DE, USA). Samples with a weight of around $11 \mathrm{mg}$ were placed in an aluminum crucible and heated from 0 to $820^{\circ} \mathrm{C}$ in a nitrogen atmosphere with a heating rate of $10^{\circ} \mathrm{C} / \mathrm{min}$ and a flow rate of $10 \mathrm{~mL} / \mathrm{min}$ and $90 \mathrm{~mL} / \mathrm{min}$. The degradation temperature at $2 \%(\mathrm{~T} 2 \%)$ and $5 \%$ (T5\%) weight loss, as well as the temperature of the maximum weight loss rate (Td), were determined from the obtained TGA curves.

Thermal properties of materials were studied using a Q1000 Differential Scanning Calorimeter (TA Instruments, New Castle, DE, USA). Samples with a weight of $8.0+0.2 \mathrm{mg}$ were placed in an aluminum hermetic pan. Firstly, the samples were equilibrated at $0{ }^{\circ} \mathrm{C}$, then heated to $340^{\circ} \mathrm{C}$ with a scan rate of $10^{\circ} \mathrm{C} / \mathrm{min}$, and cooled to $0{ }^{\circ} \mathrm{C}$ with a scan rate of $5{ }^{\circ} \mathrm{C} / \mathrm{min}$. Finally, they were heated again to $340{ }^{\circ} \mathrm{C}$ with a scan rate of $10{ }^{\circ} \mathrm{C} / \mathrm{min}$. The process was conducted in a nitrogen atmosphere. Using the Universal V4.5A TA software, the melting point $(\mathrm{Tm})$ was determined from the second heating curve and the crystallization temperature (Tc) was determined based on the cooling curve. The crystallinity content (Xc) of the PPS composites was calculated from Equation (1):

$$
\mathrm{X}_{\mathrm{c}}(\%)=\frac{\Delta \mathrm{H}_{\mathrm{c}}}{\Delta \mathrm{H}_{\mathrm{m}}^{\circ}(1-\mathrm{x})} \Delta 100 \%
$$

where $\Delta \mathrm{H}_{\mathrm{c}}$ is the enthalpy of melting taken as the area under the melting peak from the second heating curve, $\Delta \mathrm{H}^{\circ}$ m is the melting enthalpy of $100 \%$ crystalline PPS, which is $76.5 \mathrm{~J} / \mathrm{g}$ [32], and $\mathrm{x}$ is the weight fraction of MWCNT. 
An impact of MWCNTs on thermal diffusivity of PPS-based composites was determined using the laser flash apparatus (LFA 447, Netzsch, Selb, Germany) at a temperature range from $50{ }^{\circ} \mathrm{C}$ to $250{ }^{\circ} \mathrm{C}$ with steps of $50{ }^{\circ} \mathrm{C}$. Measurements were divided into two groups. The thermal diffusivity of each type of sample was calculated as an average of the measurements of the four samples. Moreover, at each temperature setpoint for each sample, the measurement was repeated five times. Samples had similar dimensions with an approximate diameter $\mathrm{d}=25 \mathrm{~mm}$ and height $\mathrm{h}=1 \mathrm{~mm}$.

To examine the influence of the processing temperature and the MWCNT content, the electrical resistivity of the produced materials was measured using a Keithley 6221/2182A (Cleveland, OH, USA) nano voltmeter and a DC source, equipped with copper electrodes. To ensure very good contact between the samples and the electrodes, a silver conductive paste (CW7100, Chemtronics, Kennesaw, GA, USA) was used. Five samples of each material with a diameter of $25 \mathrm{~mm}$ and thickness of $1 \mathrm{~mm}$ were tested in the range from $1 \mathrm{nA}$ to $1 \mathrm{~mA}$; additionally, they were cleaned with ethanol before testing. To reduce noise and thermoelectric effects, the tests were performed in the delta mode using the four-point method.

\section{Results and Discussion}

\subsection{Rheological Properties}

MWCNTs are known as additives that change the rheological properties of different thermoplastic and thermoset polymers to a large degree due to their high aspect ratio [33]. For the prepared PPS-based composites, the complex viscosity, storage, and loss modulus also change in the presence of MWCNTs, which is presented in Figure 1a, b, and c, respectively. Neat PPS possess a viscosity around $10^{1} \mathrm{~Pa} \cdot \mathrm{s}$, and it is increased by about three orders of magnitude up to the value of $10^{4} \mathrm{~Pa} \cdot \mathrm{s}$ after the addition of $2 \mathrm{wt} \% \mathrm{MWCNTs}$. For the higher MWCNT loadings, the viscosity increases up to $105 \mathrm{~Pa} \cdot \mathrm{s}$. There is no significant difference between the MWCNT concentration, especially for 8 and $10 \mathrm{wt} \%$, where the curves are practically the same. The MWCNTs' effect on the viscosity of PPS is more pronounced at low concentrations ( $2 \mathrm{wt} \%$ ) and low frequencies, which has been reported in the literature for other thermoplastic polymers [34]. It should be noted that neat PPS behaves as a Newtonian liquid with no changes in the complex viscosity within the frequency range. The addition of MWCNTs causes the disappearance of a Newtonian plateau, and all PPS/MWCNT composites show a typical shear-thinning behavior with decreasing viscosity and frequency. Similar to viscosity, storage and loss modulus increase in the presence of MWCNTs. This is an effect of the increased viscosity, and strong interactions occur between the filler and the polymer. Both moduli are raised to the value of $10^{3} \mathrm{~Pa}$ for $2 \mathrm{wt} \%$ MWCNTs. Higher MWCNT loadings cause an increase in storage and loss modulus of up to $10^{4} \mathrm{~Pa} \cdot \mathrm{s}$ or $10^{5} \mathrm{~Pa} \cdot \mathrm{s}$, respectively. Similar to the effect of viscosity, 4, 6, 8, and $10 \mathrm{wt} \%$ MWCNT content has a lower effect on storage and loss modulus. The character of the curves changes from a steep course to a frequency-independent plateau-like behavior. The literature has reported the same character of both moduli at high MWCNT concentrations, e.g., above $2 \mathrm{wt} \%$ for PEEK [35]. This is related to the rheological percolation threshold, defined as the minimum filler concentration at which the motion of the polymer chains is restricted. It can be determined from the so-called Cole-Cole plot, which is a dependence between loss and storage modulus in a logarithmic scale, as shown in Figure 1d. Neat PPS presents a linear relationship between the moduli. There is a clear divergence from the linear dependence for all composites, which means that the filler forms the structural network resulting in a more heterogeneous system. Based on the changes in storage and loss modulus, the rheological percolation threshold can be found between $0-2 \mathrm{wt} \%$ MWCNTs within the same range reported for PPS/MWCNT composites prepared by direct components mixing [17]. Finally, it should be noted that for neat PPS, the loss modulus (Figure 1c) exceeds the storage modulus (Figure 1b). Within the whole frequency range, neat PPS reveals more viscous behavior of the material. The situation alters after the 
addition of MWCNTs, and for all composites, the loss modulus is lower than the storage modulus, which results in a more elastic material.
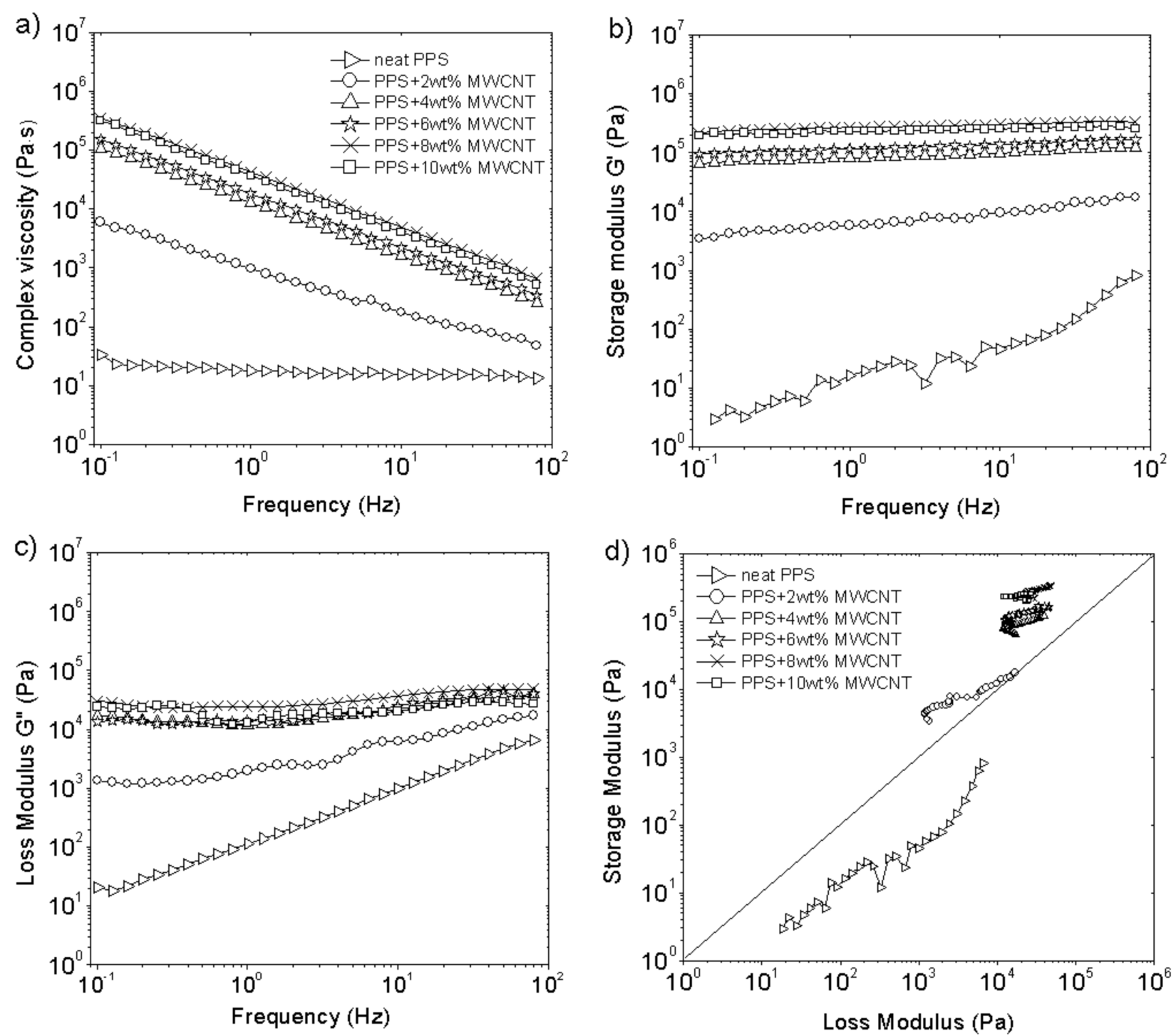

Figure 1. Rheological properties of PPS/MWCNT composites: (a) complex viscosity as a function of frequency; (b) storage modulus as a function of frequency; (c) loss modulus as a function of frequency, (d) Cole-Cole plot. The test was performed at $320^{\circ} \mathrm{C}$ with $10 \%$ strain.

\subsection{Microscope Observations}

The optical observations of non-extruded PPS $+10 \mathrm{wt} \%$ of MWCNTs were performed and the result is shown in Figure 2a. To investigate the MWCNTs' agglomerate dispersion, $10 \mathrm{wt} \%$ MWCNT masterbatch was processed at three different temperatures: $290^{\circ} \mathrm{C}, 305^{\circ} \mathrm{C}$, and $320^{\circ} \mathrm{C}$, and the optical microscopy observations are presented in Figure $2 \mathrm{~b}-\mathrm{d}$. A slight effect of temperature on the increase in the number of agglomerates was observed. This was the effect of a decrease in viscosity with an increase in temperature. However, in each of the analyzed cases, the number of MWCNT agglomerates was at a satisfactory, low level. Moreover, the effect of MWCNT content on the agglomerates dispersion was examined for the selected temperature $\left(320^{\circ} \mathrm{C}\right)$, and the results are presented in Figure 2e-h. It was observed that with a lower MWCNT content, the number of agglomerates increased. This was the effect of the viscosity change, where the shear forces may be too low for lower MWCNT contents. 


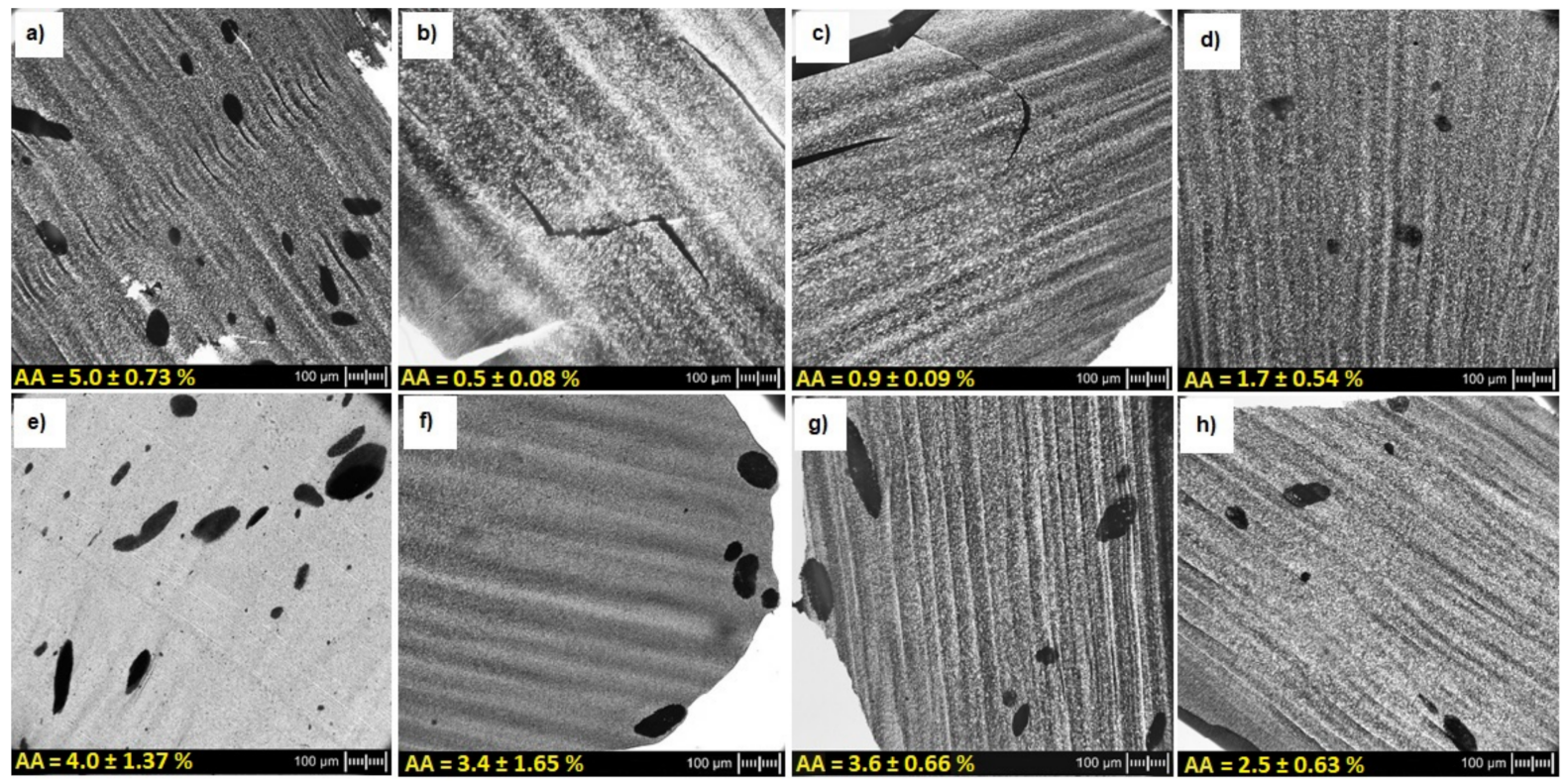

Figure 2. Optical micrographs illustrating the state of MWCNTs' agglomerate dispersion at different temperature and MWCNT content: (a) PPS + $10 \mathrm{wt} \%$ MWCNT masterbatch, (b) PPS $+10 \mathrm{wt} \%$ MWCNT $\left(\mathrm{T}=290{ }^{\circ} \mathrm{C}\right),(\mathbf{c}) \mathrm{PPS}+10 \mathrm{wt} \%$ MWCNT $\left(\mathrm{T}=305^{\circ} \mathrm{C}\right),(\mathbf{d}) \mathrm{PPS}+10 \mathrm{wt} \% \operatorname{MWCNT}\left(\mathrm{T}=320^{\circ} \mathrm{C}\right),(\mathbf{e}) \mathrm{PPS}+2 \mathrm{wt} \% \mathrm{MWCNT}\left(\mathrm{T}=320^{\circ} \mathrm{C}\right),(\mathbf{f}) \mathrm{PPS}+4 \mathrm{wt} \%$ $\operatorname{MWCNT}\left(\mathrm{T}=320^{\circ} \mathrm{C}\right),(\mathrm{g}) \operatorname{PPS}+6 \mathrm{wt} \% \operatorname{MWCNT}\left(\mathrm{T}=320^{\circ} \mathrm{C}\right),(\mathbf{h}) \mathrm{PPS}+8 \mathrm{wt} \% \operatorname{MWCNT}\left(\mathrm{T}=320^{\circ} \mathrm{C}\right)$.

To evaluate the MWCNTs' agglomerate area ratio, such optical micrographs were quantitatively evaluated by applying an image analysis procedure. The calculated CNT agglomerate area ratio confirms the decrease of agglomerates formation after applying the extrusion process to the samples and the increase in their number, along with the decrease in the content of CNTs. The influence of twin-screw extrusion conditions on nanotube dispersion is presented in the literature [36,37], which indicates that a high rotation speed and temperature are beneficial for dispersing and evenly distributing the CNT in the polymer matrix. It was found that the extrusion screw can ensure the introduction of high shear forces for CNT deagglomeration in the PPS polymer matrix. Furthermore, a better dispersion quality was achieved at higher CNT contents in the PPS matrix [38] as well as the poly(lactic acid) matrix. It was found that shear stresses as well as the viscosity of nanocomposites play an important role in destroying agglomerated nanofillers [39]. Thus, the viscosity increase resulting from the higher MWCNT content leads to higher maximum shear stresses applied to remaining CNT agglomerates. With lower CNT contents, the shear stresses can be insufficient for agglomerate breakdown.

\subsection{Thermal Properties}

The results of the thermal analysis were collected in Table 1 . The thermal stability, which is understood as the temperatures at $2 \%$ and $5 \%$ weight loss, was determined from the TGA curves. The degradation starts at $453{ }^{\circ} \mathrm{C}(2 \%)$ and $481{ }^{\circ} \mathrm{C}(5 \%)$ for neat PPS. In the starting masterbatch containing $10 \mathrm{wt} \%$ MWCNTs, the degradation temperatures are shifted to about $12-14{ }^{\circ} \mathrm{C}$, and the temperature of the maximum weight loss rate also increases by about $14{ }^{\circ} \mathrm{C}$. Further processing of the masterbatch by extrusion process resulted in the values of $\mathrm{T} 2 \%$ and $\mathrm{T} 5 \%$, which are about $3{ }^{\circ} \mathrm{C}$ higher for some of the composites, or lower for others. 
Table 1. The results of the thermal analysis.

\begin{tabular}{|c|c|c|c|c|c|c|c|}
\hline \multirow[b]{2}{*}{ Material } & \multirow{2}{*}{$\begin{array}{l}\text { Extrusion } \\
\text { Temp. }\left({ }^{\circ} \mathrm{C}\right)\end{array}$} & \multicolumn{3}{|c|}{ TGA } & \multicolumn{3}{|c|}{ DSC } \\
\hline & & $\begin{array}{l}\mathrm{T}_{2 \%} \% \\
\left({ }^{\circ} \mathrm{C}\right) \\
\end{array}$ & $\begin{array}{l}\mathrm{T}_{5 \%} \\
\left({ }^{\circ} \mathrm{C}\right)\end{array}$ & $\begin{array}{l}\mathrm{T}_{\mathrm{d}} \\
\left({ }^{\circ} \mathrm{C}\right)\end{array}$ & $\begin{array}{l}\mathrm{T}_{\mathrm{m}} \\
\left({ }^{\circ} \mathrm{C}\right)\end{array}$ & $\begin{array}{c}X_{c} \\
(\%)\end{array}$ & $\begin{array}{c}\mathrm{T}_{\mathrm{c}} \\
\left({ }^{\circ} \mathrm{C}\right)\end{array}$ \\
\hline neat PPS & & 453 & 481 & 521 & 283 & 54.5 & 228 \\
\hline PPS $+10 \%$ masterbatch & & 467 & 493 & 535 & 286 & 59.3 & 257 \\
\hline $\mathrm{PPS}+2 \% \mathrm{MWCNT}$ & \multirow{5}{*}{290} & 456 & 486 & 531 & 287 & 66.5 & 256 \\
\hline $\mathrm{PPS}+4 \% \mathrm{MWCNT}$ & & 452 & 484 & 532 & 287 & 53.2 & 257 \\
\hline $\mathrm{PPS}+6 \% \mathrm{MWCNT}$ & & 451 & 483 & 535 & 286 & 61.8 & 257 \\
\hline PPS + 8\% MWCNT & & 453 & 484 & 533 & 286 & 58.7 & 257 \\
\hline PPS + 10\% MWCNT & & 451 & 482 & 530 & 287 & 65.3 & 257 \\
\hline $\mathrm{PPS}+2 \% \mathrm{MWCNT}$ & \multirow{5}{*}{305} & 454 & 487 & 535 & 287 & 57.3 & 256 \\
\hline $\mathrm{PPS}+4 \% \mathrm{MWCNT}$ & & 453 & 484 & 531 & 286 & 53.3 & 258 \\
\hline PPS + 6\% MWCNT & & 454 & 485 & 534 & 287 & 58.9 & 257 \\
\hline PPS + 8\% MWCNT & & 454 & 484 & 534 & 286 & 73.1 & 257 \\
\hline $\mathrm{PPS}+10 \% \mathrm{MWCNT}$ & & 457 & 486 & 535 & 286 & 61.1 & 257 \\
\hline $\mathrm{PPS}+2 \% \mathrm{MWCNT}$ & \multirow{5}{*}{320} & 452 & 484 & 533 & 286 & 60.6 & 255 \\
\hline $\mathrm{PPS}+4 \% \mathrm{MWCNT}$ & & 457 & 487 & 532 & 287 & 67.5 & 257 \\
\hline $\mathrm{PPS}+6 \% \mathrm{MWCNT}$ & & 454 & 484 & 534 & 287 & 65.7 & 257 \\
\hline PPS $+8 \%$ MWCNT & & 456 & 486 & 538 & 287 & 64.1 & 257 \\
\hline $\mathrm{PPS}+10 \% \mathrm{MWCNT}$ & & 453 & 483 & 534 & 286 & 54.1 & 257 \\
\hline
\end{tabular}

The temperature of the maximum weight loss is significantly improved by about $10-17{ }^{\circ} \mathrm{C}$ for all composites compared with the maximum weight loss rate. There is no apparent effect of the extrusion temperature and MWCNT content on the thermal stability of PPS/MWCNT composites. Because both T2\% and T5\% are the highest for the masterbatch, the additional processing step decreases the thermal stability in view of initiating the degradation process. The calculated amount of the agglomerates is presented in Figure 2. Many more MWCNT agglomerates were found in the masterbatch than in the composites after processing. It seems that the presence of agglomerates is more critical for thermal stability improvement than perfectly dispersed MWCNTs. More agglomerates in the composites hinder the flux of degradation products more effectively than single MWCNTs. It might also be that PPS chains near the MWCNT agglomerates degrade slowly, but only if they are homogenously dispersed [40]. The other possible mechanism is that the second extrusion step causes some degradation of the PPS chains, and therefore, the composites start to decompose at a lower temperature. Most of the nanofiller works as a nucleating agent for the polymers.

The analysis of the effect of MWCNT addition on the crystallization phenomenon of PPS was carried out using the DSC method. The determined meting point Tm, crystallization temperature Tc, and calculated crystallinity degree $\mathrm{Xc}_{\mathrm{c}}$ are included in Table 1. The melting point of neat PPS is $283^{\circ} \mathrm{C}$, and it shifts to the value of $286-287^{\circ} \mathrm{C}$. An example thermogram comparing the effect of MWCNTs on the melting point and extrusion temperature is shown in Figure 3a,b. 

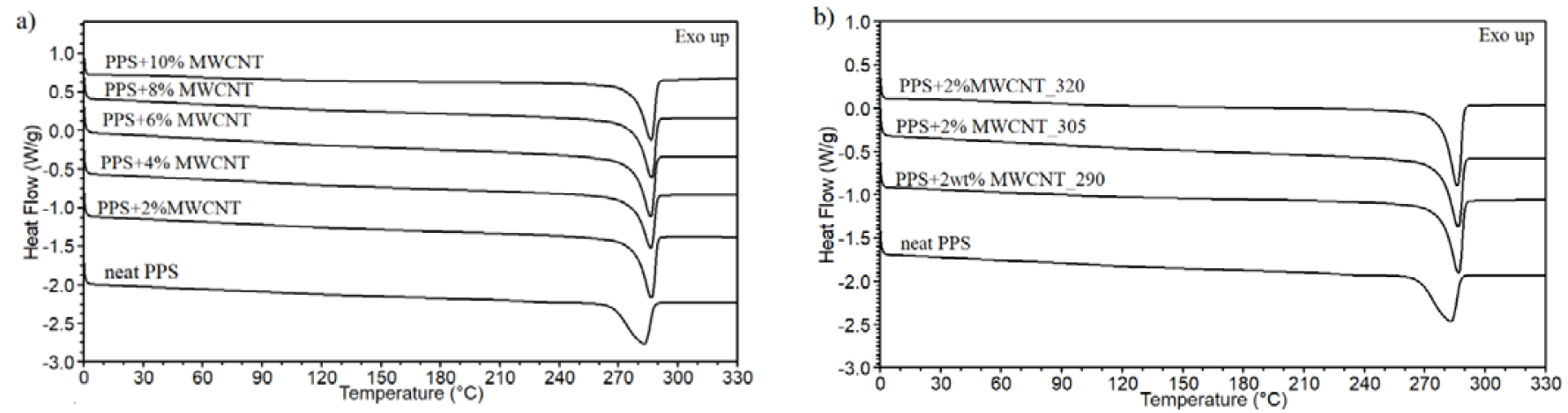

Figure 3. The second heating curve for the PPS/MWCNT composites. (a) Comparison of the MWCNT content. (b) Comparison of the extrusion temperature.

There is no effect of the MWCNT content and extrusion temperature on the melting point. Moreover, the melting peak of neat PPS is broad, and it is getting narrower for PPS/MWCNT composites, which reveals the changes in the crystal phase of the polymer, as demonstrated by an increase in the crystallinity degree and crystallization temperature. As shown in Table 1, for most of the composites, the addition of MWCNTs causes an increase in the crystallinity content at a maximum of $18 \%$ and an increase in the crystallization temperature of $29^{\circ} \mathrm{C}$. The nucleation effect of MWCNTs on PPS is visible by a significant shift in the crystallization peak, as presented in Figure $4 \mathrm{a}, \mathrm{b}$.
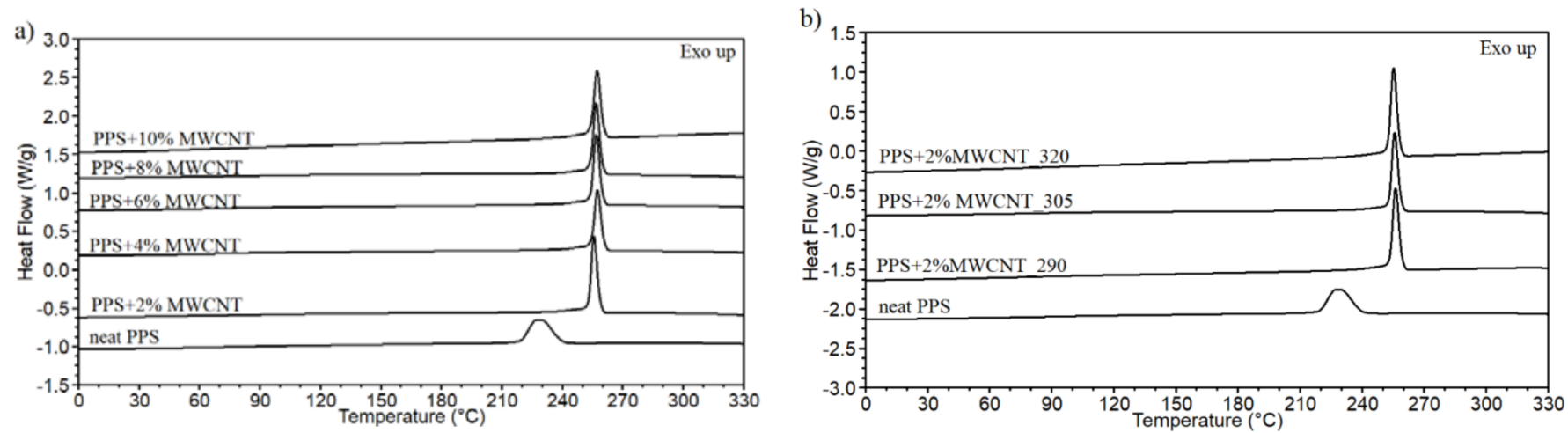

Figure 4. The cooling curves for the PPS/MWCNT composites. (a) Comparison of the MWCNT content. (b) Comparison of the extrusion temperature.

The graphs also confirm no evident influence of MWCNT concentration and extrusion temperature on the crystallization phenomena. It is confirmed by a similar value of the crystallization temperature $\left(256-258{ }^{\circ} \mathrm{C}\right)$ obtained for all composites. A similar lack of linear dependence between crystallinity content and nanotube concentration was found in PA6 containing MWCNTs [41]. In the other PPS/MWCNT composites prepared by direct components mixing, the nucleating effect of MWCNTs was observed, but only for small nanotube concentrations. At higher concentrations, the melting point and crystallinity degree show a gradual decrease. Probably, the created MWCNT network hinders the movement of the polymer chains leading to forming of an imperfect crystal phase [17].

The thermal diffusivity of all PPS/MWCNT composites is shown in Figure 5a,b. Figure 5a presents the thermal diffusivity decreasing with temperature. In addition, MWCNTs affect the thermal diffusivity of PPS-based composites. The higher the weight fraction of MWCNTs, the higher the thermal diffusivity. Maximum value $\mathrm{a}=0.255 \mathrm{~mm} \cdot \mathrm{s}^{-1}$ was determined for samples PPS $+10 \mathrm{wt} \% \mathrm{MWCNT}$ at the temperature $\mathrm{T}=50{ }^{\circ} \mathrm{C}$. On the other hand, neat PPS has lower thermal diffusivity of $\mathrm{a}=0.144 \mathrm{~mm} \mathrm{~m}^{2} \cdot \mathrm{s}^{-1}$ at the same temperature. That compared with samples containing $10 \mathrm{wt} \%$ MWCNT gives a maximum increase of 
approximately $77 \%$. At maximum measured temperature $\mathrm{T}=250{ }^{\circ} \mathrm{C}$, the thermal diffusivity of a sample with maximum loading increases by $38 \%$ compared with neat PPS. The increase in thermal diffusivity with an increasing MWCNT weight fraction is close to linear. The achieved increase in thermal diffusivity of PPS/MWCNT composites with this type of filler is rather low when compared with other authors [19]. However, since a different filler was used, the carbon MWCNT feature is extremely high for a specific surface area. It is higher than in other allotropes of carbon-based fillers and causes higher interfacial resistance, which deteriorates heat conduction through the material.

a)

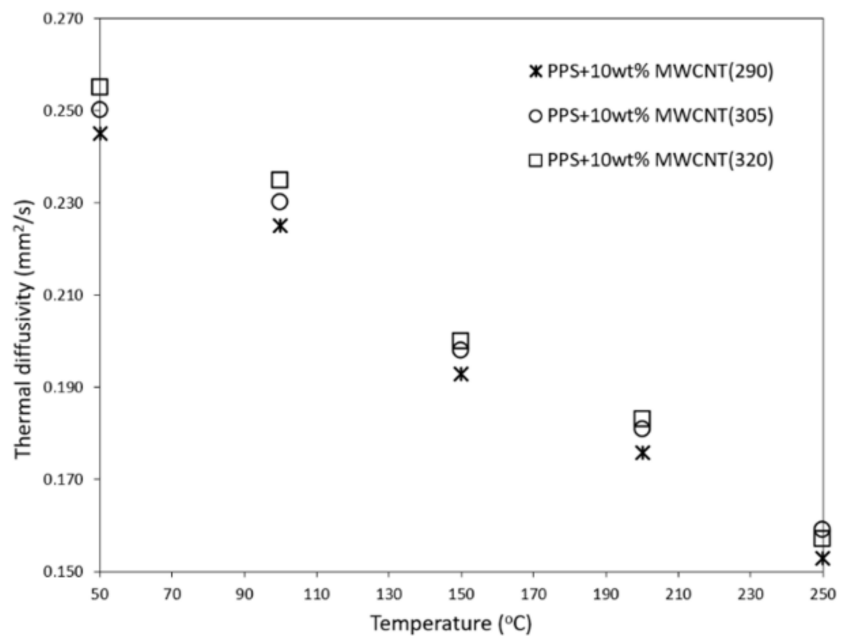

b)

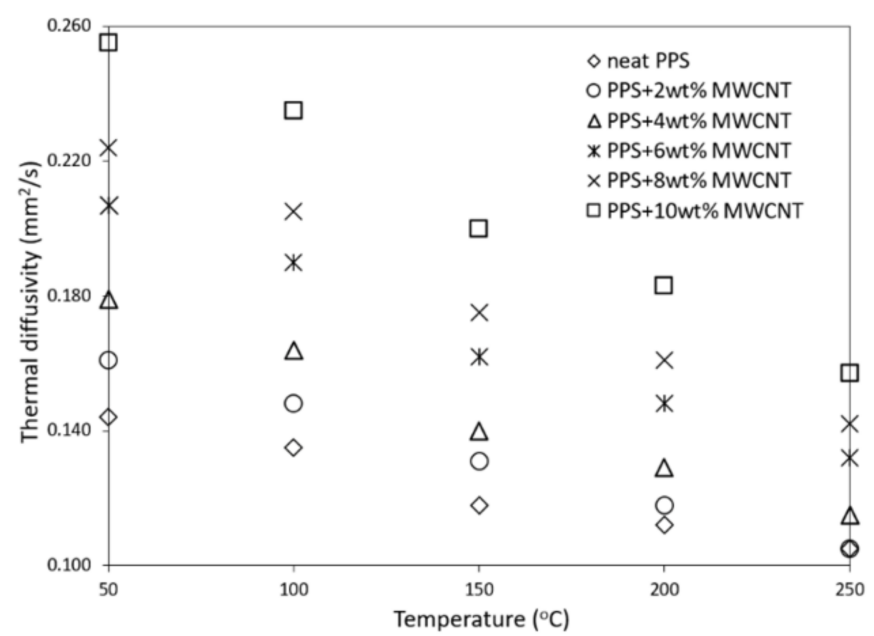

Figure 5. Thermal diffusivity vs. (a) temperature of PPS-based composites filled with MWCNT and (b) temperature of PPS-based composite manufactured with different temperature.

Figure $5 b$ shows the impact of the extrusion temperature on the thermal diffusivity of the tested samples. The higher the temperature, the higher the thermal diffusivity, but it increases the maximum by approximately $4 \%$ for samples PPS $+10 \mathrm{wt} \%$ MWCNT $\left(\mathrm{T}=320^{\circ} \mathrm{C}\right)$ compared with PPS $+10 \mathrm{wt} \%\left(\mathrm{~T}=290^{\circ} \mathrm{C}\right)$.

\subsection{Electrical Properties}

The influence of the MWCNT content and processing temperature on the level of electrical conductivity of PPS/MWCNT nanocomposites has been examined and the results are presented in Figure 6. The largest increase in electrical conductivity was observed from $10^{-11} \mathrm{~S} / \mathrm{m}$ for neat PPS to $7 \cdot 10^{-5} \mathrm{~S} / \mathrm{m}$ for $2 \mathrm{wt} \%$ MWCNT, and this increase was almost six orders of magnitude. Then, the increase in conductivity slowed down and increased linearly from 2 to $6 \%$ in the MWCNT content, after which it slowed significantly, and the increase in concentration from 6 to $10 \%$ of MWCNT improved by one order of magnitude, finally reaching values of about $10^{0}$.

By analyzing the results and the conductivity curve, the electrical percolation threshold can be established between $0-2 \mathrm{wt} \%$ of MWCNTs. This value is relatively low compared with the values obtained in the literature at $5 \%$ of the MWCNT content [17], which proves good MWCNT dispersion in the PPS matrix. It was achieved by the selection of appropriate temperature and double extrusion on a twin-screw extruder. It was also the effect of using MWCNTs from Nanocyl, which possess very good properties as a conductive filler. Using them to make conductive nanocomposites is known in the literature and the obtained percolation threshold for these MWCNTs is about $1 \mathrm{wt} \%$ [42,43]. Moreover, it was observed that the change of the processing temperature from $290{ }^{\circ} \mathrm{C}$ to $320^{\circ} \mathrm{C}$ did not affect the electrical conductivity. The greatest change was observed for nanocomposites with $10 \mathrm{wt} \%$ MWCNT content, where the electrical conductivity was $8.39 \cdot 10^{-1} \mathrm{~S} / \mathrm{m}$ and $1.05 \cdot 10^{0} \mathrm{~S} / \mathrm{m}$ for $290^{\circ} \mathrm{C}$ and $320^{\circ} \mathrm{C}$, respectively. This is the result of a slight difference in the state of MWCNTs' agglomerate dispersion, which is presented in Figure 2. 


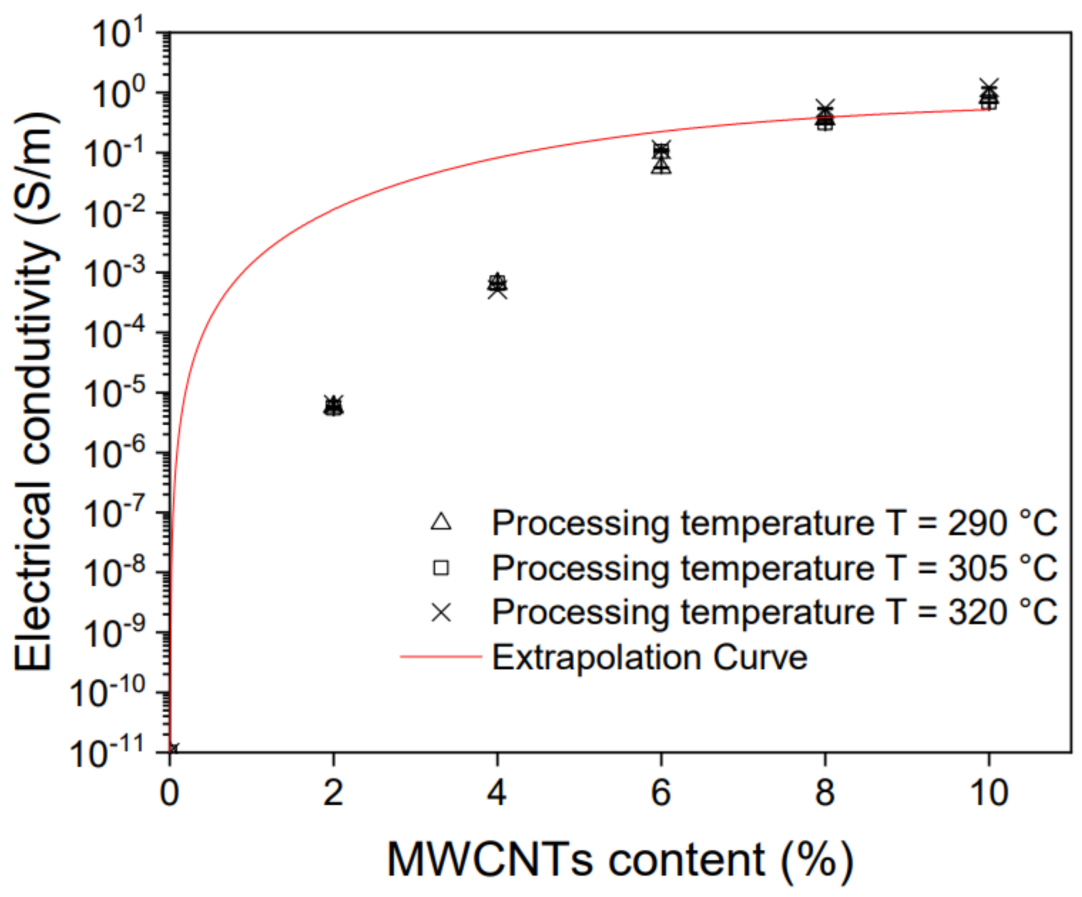

Figure 6. Electrical conductivity of PPS/MWCNT nanocomposites.

\section{Conclusions}

The present work investigated the effect of processing temperature and the content of carbon nanotubes on the properties of nanocomposites based on PPS. The studies aimed to select the best material and processing parameters for the production of thermoplastic veils with the addition of MWCNTs, as a unique technique to improve the properties of CFRP. For this purpose, PPS/MWCNT nanocomposites were produced at three different temperatures and with different filler contents. TGA analysis showed a slight decrease in thermal stability for the produced nanocomposites compared with a masterbatch with an MWCNT content of $10 \mathrm{wt} \%$. This may be the result of the subsequent processing of the material, as the MWCNT content was not found to affect thermal stability. In the case of DSC analysis, the content of MWCNTs and the processing temperature do not affect the melting point; however, the addition of MWCNT causes an increase in the degree of crystallinity and the crystallization temperature. The highest values of thermal diffusivity and electrical conductivity were observed in nanocomposites containing $8-10 \mathrm{wt} \%$ MWCNTs, which was caused by the excellent thermal and electrical properties of MWCNTs. Viscosity studies showed that the addition of $2 \%$ MWCNT makes the material more elastic than plastic. Additionally, no significant effect of the amount of filler on the rheological properties was observed for higher MWCNT concentrations. In the case of microscopic observations, a larger area of agglomerates was observed for lower concentrations of MWCNTs, which is the result of lower nanocomposite viscosity, and consequently, lower shear forces during processing. The same was observed as regards the influence of the processing temperature-as the processing temperature increases, the viscosity decreases, which translates into lower shear forces and worse homogenization of the nanocomposite. Taking into account the obtained results, it was found that the content of MWCNTs within the range of $8-10 \mathrm{wt} \%$ and the processing temperature from 305 to $320^{\circ} \mathrm{C}$ allows for obtaining the desired properties of the PPS/MWCNT nanocomposites, which will be the basis for thermoplastic nonwovens, used to improve the properties of CFRPs. 
Author Contributions: Conceptualization, K.D.; methodology, K.D., P.L.-D., S.D., P.K., M.K. and A.S.; software, K.D., S.D. and A.S.; validation, K.D., P.L.-D. and B.S.; formal analysis, K.D.; investigation, K.D., P.L.-D., P.K. and M.K.; resources, K.D.; writing-original draft preparation, K.D.; writingreview and editing, A.B. and B.S.; visualization, K.D., P.L.-D., M.K. and P.K.; supervision, A.B.; project administration, K.D.; acquiring funds, K.D. All authors have read and agreed to the published version of the manuscript.

Funding: This study was carried out with funding from grant no. LIDER/46/0185/L-11/19/NCBR/2020, financed by The National Centre for Research and Development.

Institutional Review Board Statement: Not applicable.

Informed Consent Statement: Not applicable.

Data Availability Statement: All data are available in the main text.

Conflicts of Interest: The authors declare no conflict of interest.

\section{References}

1. Corea, J.R.; Flynn, A.M.; Lechêne, B.; Scott, G.; Reed, G.D.; Shin, P.J.; Lustig, M.; Arias, A.C. Screen-printed flexible MRI receive coils. Nat. Commun. 2016, 7, 1-7. [CrossRef] [PubMed]

2. Schwartz, C.J.; Bahadur, S. The role of filler deformability, filler-polymer bonding, and counterface material on the tribological behavior of polyphenylene sulfide (PPS). Wear 2001, 250, 1532-1540. [CrossRef]

3. Menzel, F.; Klein, T.; Ziegler, T.; Neumaier, J.M. 3D-printed PEEK reactors and development of a complete continuous flow system for chemical synthesis. React. Chem. Eng. 2020, 5, 1300-1310. [CrossRef]

4. Yu, L.; Yang, S.; Liu, W.; Xue, Q. Investigation of the friction and wear behaviors of polyphenylene sulfide filled with solid lubricants. Polym. Eng. Sci. 2000, 40, 1825-1832. [CrossRef]

5. Deng, Y.; Yang, Y.; Ma, Y.; Fan, K.; Yang, W.; Yin, G. Nano-hydroxyapatite reinforced polyphenylene sulfide biocomposite with superior cytocompatibility and in vivo osteogenesis as a novel orthopedic implant. RSC Adv. 2017, 7, 559-573. [CrossRef]

6. Kulpinski, P.; Czarnecki, P.; Niekraszewicz, B.; Jeszka, J.K. Functional nanocomposite poly(phenylene sulphide) fibresPreliminary studies. Fibres Text. East. Eur. 2016, 24, 20-26. [CrossRef]

7. Zuo, P.; Tcharkhtchi, A.; Shirinbayan, M.; Fitoussi, J.; Bakir, F. Overall Investigation of Poly (Phenylene Sulfide) from Synthesis and Process to Applications-A Review. Macromol. Mater. Eng. 2019, 304, 1-27. [CrossRef]

8. Rahate, A.S.; Nemade, K.R.; Waghuley, S.A. Polyphenylene sulfide (PPS): State of the art and applications. Rev. Chem. Eng. 2013, 29, 471-489. [CrossRef]

9. Lv, C.; Wang, H.; Liu, Z.; Wang, C.; Li, H.; Zhao, Y.; Zhu, Y. A fluorine-free superhydrophobic PPS composite coating with high thermal stability, wear resistance, corrosion resistance. Prog. Org. Coatings 2017, 110, 47-54. [CrossRef]

10. Chen, G.; Mohanty, A.K.; Misra, M. Progress in research and applications of Polyphenylene Sulfide blends and composites with carbons. Compos. Part B Eng. 2021, 209, 108553. [CrossRef]

11. Yu, Y.; Xiong, S.; Huang, H.; Zhao, L.; Nie, K.; Chen, S.; Xu, J.; Yin, X.; Wang, H.; Wang, L. Fabrication and application of poly (phenylene sulfide) ultrafine fiber. React. Funct. Polym. 2020, 150, 104539. [CrossRef]

12. Liang, J.Z. Heat distortion temperature of PPS/PC blend, PPS/PC nanocomposite and PPS/PC/GF hybrid nanocomposite. J. Polym. Eng. 2013, 33, 483-488. [CrossRef]

13. Ma, Z.; Zhang, G.; Yang, Q.; Shi, X.; Li, J.; Zhang, H.; Qin, J. Tailored morphologies and properties of high-performance microcellular poly(phenylene sulfide)/poly(ether ether ketone) (PPS/PEEK) blends. J. Supercrit. Fluids 2018, 140, 116-128. [CrossRef]

14. Jiang, Z.; Gyurova, L.A.; Schlarb, A.K.; Friedrich, K.; Zhang, Z. Study on friction and wear behavior of polyphenylene sulfide composites reinforced by short carbon fibers and sub-micro TiO2 particles. Compos. Sci. Technol. 2008, 68, 734-742. [CrossRef]

15. Zhang, Z.; Zhou, W.; Li, Y.; Yan, C. Isothermal crystallization kinetics of poly(phenylene sulfide)/ZnO composites. Adv. Mater. Res. 2012, 535-537, 243-246. [CrossRef]

16. Goyal, R.K.; Kambale, K.R.; Nene, S.S.; Selukar, B.S.; Arbuj, S.; Mulik, U.P. Fabrication, thermal and electrical properties of polyphenylene sulphide/copper composites. Mater. Chem. Phys. 2011, 128, 114-120. [CrossRef]

17. Yang, J.; Xu, T.; Lu, A.; Zhang, Q.; Tan, H.; Fu, Q. Preparation and properties of poly (p-phenylene sulfide)/multiwall carbon nanotube composites obtained by melt compounding. Compos. Sci. Technol. 2009, 69, 147-153. [CrossRef]

18. Park, M.; Park, J.H.; Yang, B.J.; Cho, J.; Kim, S.Y.; Jung, I. Enhanced interfacial, electrical, and flexural properties of polyphenylene sulfide composites filled with carbon fibers modified by electrophoretic surface deposition of multi-walled carbon nanotubes. Compos. Part A Appl. Sci. Manuf. 2018, 109, 124-130. [CrossRef]

19. Seki, Y.; Kizilkan, E.; İşbilir, A.; Sarikanat, M.; Altay, L. Enhanced in-plane and through-plane thermal conductivity and mechanical properties of polyamide 4.6 composites loaded with hybrid carbon fiber, synthetic graphite and graphene. Polym. Compos. 2021, 42, 4630-4642. [CrossRef] 
20. Deng, S.; Lin, Z.; Xu, B.; Qiu, W.; Liang, K.; Li, W. Isothermal crystallization kinetics, morphology, and thermal conductivity of graphene nanoplatelets/polyphenylene sulfide composites. J. Therm. Anal. Calorim. 2014, 118, 197-203. [CrossRef]

21. Gu, J.; Xie, C.; Li, H.; Dang, J.; Geng, W.; Zhang, Q. Thermal Percolation Behavior of Graphene Nanoplatelets/Polyphenylene Sulfide Thermal Conductivity Composites Junwei. Polym. Compos. 2014, 35, 1087-1092. [CrossRef]

22. Xing, J.; Xu, Z.; Ni, Q.Q.; Ke, H. Preparation and characterization of polyphenylene sulfide/graphene nanoplatelets composite fibers with enhanced oxidation resistance. High Perform. Polym. 2020, 32, 394-405. [CrossRef]

23. Retolaza, J.; Ansola, R.; Gómez, J.L.; Díez, G. Identifying elastic constants for pps technical material when designing and printing parts using fdm technology. Materials 2021, 14, 1-19. [CrossRef] [PubMed]

24. Parans Paranthaman, M.; Yildirim, V.; Lamichhane, T.N.; Begley, B.A.; Post, B.K.; Hassen, A.A.; Sales, B.C.; Gandha, K.; Nlebedim, I.C. Additive manufacturing of isotropic NdFeB PPS bonded permanent magnets. Materials 2020, 13, 1-10. [CrossRef] [PubMed]

25. Boczkowska, A.; Latko, P. Sposób Wytwarzania Włókien i Włókniny z Nanorurkami Węglowymi. Polish Patent Pl 221848 B1, 30 June 2016.

26. Dydek, K.; Latko-Durałek, P.; Boczkowska, A.; Sałaciński, M.; Kozera, R. Carbon Fiber Reinforced Polymers Modified with Thermoplastic Nonwovens Containing Multi-Walled Carbon Nanotubes. Compos. Sci. Technol. 2019, 173, 110-117. [CrossRef]

27. Latko-Durałek, P.; Dydek, K.; Golonko, E.; Boczkowska, A. Mechanical properties of PETG fibres and their usage in carbon fibres/epoxy composite laminates. Fibres Text. East. Eur. 2018, 26. [CrossRef]

28. Latko-Duralek, P.; Dydek, K.; Bolimowski, P.; Golonko, E.; Duralek, P.; Kozera, R.; Boczkowska, A. Nonwoven fabrics with carbon nanotubes used as interleaves in CFRP. IOP Conf. Ser. Mater. Sci. Eng. 2018, 406, 012033. [CrossRef]

29. Quan, D.; Mischo, C.; Binsfeld, L.; Ivankovic, A.; Murphy, N. Fracture behaviour of carbon fibre/epoxy composites interleaved by MWCNT- and graphene nanoplatelet-doped thermoplastic veils. Compos. Struct. 2020, 235, 111767. [CrossRef]

30. Dydek, K.; Boczkowska, A.; Latko-Durałek, P.; Wilk, M.; Padykuła, K.; Kozera, R. Effect of the areal weight of CNT-doped veils on CFRP electrical properties. J. Compos. Mater. 2020, 54, 2677-2685. [CrossRef]

31. Kasaliwal, G.R.; Pegel, S.; Göldel, A.; Pötschke, P.; Heinrich, G. Analysis of agglomerate dispersion mechanisms of multiwalled carbon nanotubes during melt mixing in polycarbonate. Polymer 2010, 51, 2708-2720. [CrossRef]

32. Nohara, L.B.; Nohara, E.L.; Moura, A.; Gonçalves, J.M.R.P.; Costa, M.L.; Rezende, M.C. Study of crystallization behavior of poly(phenylene sulfide). Polimeros 2006, 16, 104-110. [CrossRef]

33. Nobile, M.R. Rheology of Polymer-Carbon Nanotube Composites Melts; Woodhead Publishing Limited: Sawstln, UK, 2011; ISBN 9781845697617.

34. Jin, S.H.; Choi, D.K.; Lee, D.S. Electrical and rheological properties of polycarbonate/multiwalled carbon nanotube nanocomposites. Colloids Surf. Physicochem. Eng. Asp. 2008, 313-314, 242-245. [CrossRef]

35. Bangarusampath, D.S.; Ruckdäschel, H.; Altstädt, V.; Sandler, J.K.W.; Garray, D.; Shaffer, M.S.P. Rheological and electrical percolation in melt-processed poly(ether ether ketone)/multi-wall carbon nanotube composites. Chem. Phys. Lett. 2009, 482, 105-109. [CrossRef]

36. Pegel, S.; Pötschke, P.; Petzold, G.; Alig, I.; Dudkin, S.M.; Lellinger, D. Dispersion, agglomeration, and network formation of multiwalled carbon nanotubes in polycarbonate melts. Polymer 2008, 49, 974-984. [CrossRef]

37. Villmow, T.; Kretzschmar, B.; Pötschke, P. Influence of screw configuration, residence time, and specific mechanical energy in twin-screw extrusion of polycaprolactone/multi-walled carbon nanotube composites. Compos. Sci. Technol. 2010, 70, 2045-2055. [CrossRef]

38. Noll, A.; Burkhart, T. Morphological characterization and modelling of electrical conductivity of multi-walled carbon nanotube/poly(p-phenylene sulfide) nanocomposites obtained by twin screw extrusion. Compos. Sci. Technol. 2011, 71, 499-505. [CrossRef]

39. Villmow, T.; Pötschke, P.; Pegel, S.; Häussler, L.; Kretzschmar, B. Influence of twin-screw extrusion conditions on the dispersion of multi-walled carbon nanotubes in a poly(lactic acid) matrix. Polymer 2008, 49, 3500-3509. [CrossRef]

40. Moniruzzaman, M.; Winey, K.I. Polymer nanocomposites containing carbon nanotubes. Macromolecules 2006, $39,5194-5205$. [CrossRef]

41. Fornes, T.D.; Paul, D.R. Crystallization behavior of nylon 6 nanocomposites. Polymer 2003, 44, 3945-3961. [CrossRef]

42. Krause, B.; Villmow, T.; Boldt, R.; Mende, M.; Petzold, G.; Pötschke, P. Influence of dry grinding in a ball mill on the length of multiwalled carbon nanotubes and their dispersion and percolation behaviour in melt mixed polycarbonate composites. Compos. Sci. Technol. 2011, 71, 1145-1153. [CrossRef]

43. Socher, R.; Krause, B.; Hermasch, S.; Wursche, R.; Pötschke, P. Electrical and thermal properties of polyamide 12 composites with hybrid fillers systems of multiwalled carbon nanotubes and carbon black. Compos. Sci. Technol. 2011, 71, 1053-1059. [CrossRef] 